\title{
Thermal Analysis and Climate Control of Experimental two-level Hydroponic Growth Cell
}

\author{
Helena Vitoshkin ${ }^{1}$, Vitaly Haslavsky ${ }^{2}$ \\ ${ }^{1}$ Agricultural Research Organization, The Volcani Center \\ P.O.Box 6, 5025001, 68 Dereh Hamacabim, Rishon lesion, Israel \\ elenav@volcani.agri.gov.il \\ ${ }^{2}$ Azrieli College of Engineering \\ 26 Yaakov Shreibom Street, Jerusalem, Israel \\ vitaliha@jce.ac.il
}

\begin{abstract}
The research focuses on providing optimal conditions for growth, energy efficiency, and sustainability, controlled and autonomous environment. A two-level hydroponic growth cell is proposed as an experimental facility to design of in-door multilayer plant production systems. The goal of the system is to serve as a practical and useful alternative to traditional field agriculture. The growth cell has of $1 \mathrm{~m}^{2}$ each level area and composites two rows of hydroponic growth elements. The cell is designed to carry out multiple functions essential to sustain plant growth that includes: water circulation, nutrients delivery, environment sensing, ventilation, and artificial selective lighting. The series of repeated growth cycles have been successfully performed and compared against a conventional greenhouse facility using lettuce as a model crop. The factors such as inside temperature and humidity, leaf temperature, illumination under three different lighting types: white light, red-blue light, sunlight were monitored and maintained by a developed control system. Light distribution (photosynthetic active radiation) and yield (leaf size and fresh weight) were assessed. It is shown that sunlight is the more profitable type of lighting for lettuce crops even under warm outside environmental conditions. These results illustrate that the use of transparent covering materials offer great potential for energy save cultivation and should be considered for a plant-factory design.
\end{abstract}

Keywords: plant factory, energy efficiency, and sustainability, cogeneration

\section{Introduction}

As the population is growing, the need for food supply is increasing. Agriculture land occupies a large area, and despite all obstacles, the crop industry has to supply high-quality products daily, according to market commitment. Instead of farming vegetables and other foods on a single level, such as in a field or a greenhouse, the vertical farming method produces foods in vertically stacked layers commonly integrated into other structures like a skyscraper, shipping container, or repurposed warehouse [1]-[4]. Moreover, food production has widespread effects on public health, water, land, and economic development [5]. The artificial control of temperature, light, humidity, and gases makes producing foods and medicine indoor possible, while the primary goal is maximizing crop output in a limited space. Vertical farming allows for year-round production, close to urban centers, and less susceptible to weather extremes.

There are many reports in literature illustrating a high variety of vertical in-door farm types frequently investigated by both commercial and research protected horticulture facilities (for example [6], [7]). Such crops as usually leafy vegetables, including lettuce and herbs, tomato, and pepper are grown in large-scale houses using hydroponic systems [8]. Alternatively, plants can be grown in hydroponic [9], or aeroponics nutrient solutions [10], or aquaponics (nutrient provision from waste from a fish farm built into the recirculation system [11]. Although the agronomic parameters and lighting models are already widely investigated, the modeling of microclimatic performance is still insufficient.

The aim of the paper to examine microclimate inside the two-layer growth cell by implementing different types of thermal analysis. The purpose is to compare conditions between two layers in terms of the following parameters: spatial temperature and humidity distribution, light intensity and quality, plant leaf temperature and transpiration rate, airflow rate, various external environmental conditions, and finely, crop parameters like leaf size and quality and overall weight of plants. 


\section{Material and Methods}

We design a modular research facility that will respond as widely as possible to in-door multilayer growth experiments. We are interested in investigating and testing different aspects of climate control suitable for a wide range of vegetables and herbs cultivations. The study was conducted in a $2.0 \mathrm{~m} \times 1.7 \mathrm{~m}$ two-level controlled environment chamber, with $1 \mathrm{~m}^{2}$ of area of each level. Illumination was provided by commercial plant grow LED lamps 240W with two different spectral characteristics: white (W) and red-blue (RB) LED lamps with a ratio of three ([12], [13], [14]). A photosynthetic photon flux density of $200 \mu \mathrm{mol} \mathrm{m}^{-2} \mathrm{~s}^{-1}$ was provided for 10 hours per day (from 06:00 to 16:00). Polyethylene air bubble sheet covered with highly reflective aluminum foil was placed on the walls of the chamber in order to increase the thermal insulation and the diffusion of light. Inside air temperature was measured by six T-type thermocouples $\left( \pm 0.1^{\circ} \mathrm{C}\right.$ accuracy after calibration by PT100 platinum resistance thermometer), three sensors at each level: in the vicinity of the lamp, in the middle, and near the crop. Inside air humidity was recorded by two digital humidity sensors $( \pm 3.5 \% \mathrm{RH}$ accuracy), one at each level, which were hanging from the ceiling in the middle of the level, at $40 \mathrm{~cm}$ above the growing tubes. Each level was equipped with two PAR (Quantum, measurement repeatability <1\%) sensors for lighting intensity monitoring and control. Hydroponic pipes and pump system provided circulating water with a nutrient solution. The nutrient solution was qualified by electrical conductivity. The inside climate parameters such as temperature, humidity, and radiation were reordered by every 10 seconds and averaged over every one minute via data-logger . Ventilation rate, lamp lighting, and water level adjustment were controlled by programmed PLC Unitronics controller. The ventilation rate of $100 \mathrm{~m}^{3} / \mathrm{h}$ in average was activated when the air temperature in the chamber increased more than $26^{\circ} \mathrm{C}$ and relative humidity more than $80 \%$. The external environmental conditions recorded by the local meteorological station. The leaf temperature was measured by both thermocouples (for monitoring) and thermal infra-red camera (for the spatial distribution of leaf temperature). Figure 1 illustrates the growth cell, measurements, and control instruments schematically.

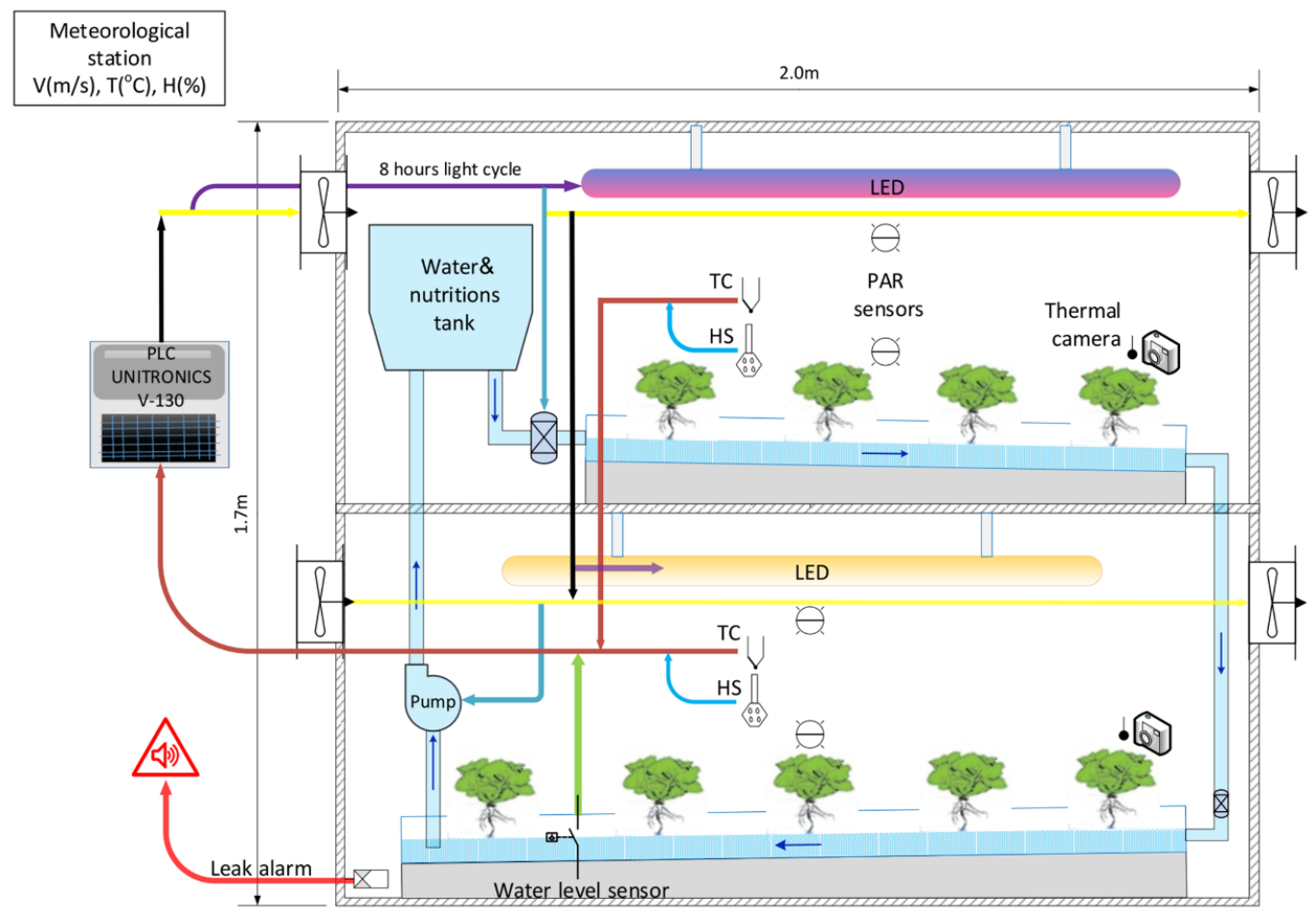

Fig. 1: Schematic view of the experimental growth cell, measurements, and control systems. 
The experiments were conducted at three growth cycles with different lighting and ambient conditions using lettuce as a model crop. Two growth cycles of measurements took place in a shelter in order to minimize the effect of unstable ambient conditions. The W LED lamps were used at each level for the first cycle, while in the second cycle, RB LEDs were installed on the upper level. The third growth cycle was conducted at natural outside conditions. The upper level was opened to the sunlight with $30 \%$ shading, while the lower level was lighted by W LED. The first cycle was established as a reference case, while two other cycles represent study cases of extremely different climatic conditions.

\section{Results}

Three growth cycles were performed to analyze the microclimate within each level of the growth system (Figure 1a). Significant differences in fresh plant weight and longitudinal leaf size during growth under RB and W light were detected. In terms of plant growth rate and quality, the best results were obtained for the natural sun growth cycle, when the plants have reached the similar crop parameters almost twice faster in comparison with both LED lighting types (Figure 1b). RB lighting type demonstrates very low productivity. A possible explanation for this is the significant influence of microclimate conditions under selective lighting. In opposite, while the plant receives the entire spectrum of light or natural sunlight, it is more stable and easier to adapt to various conditions.

a)

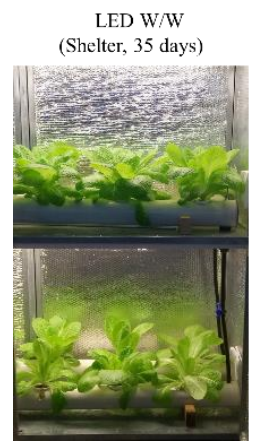

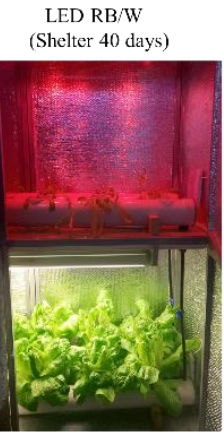

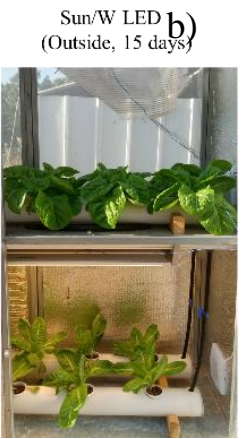

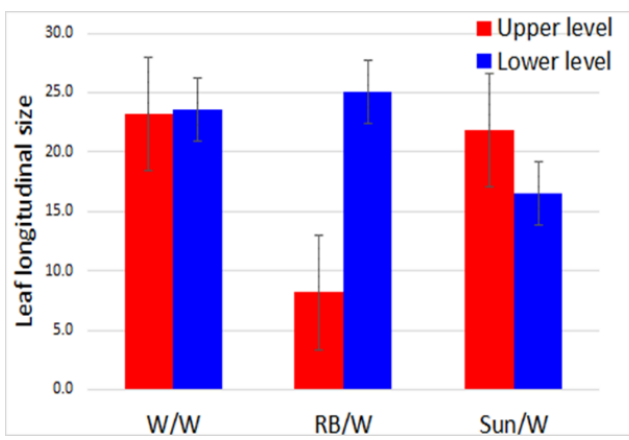

Fig. 2: (a) three lettuce growth cycles; (b) leaf size comparison between three growth cycles in two levels.

Figure 3a illustrates the typical spatial temperature measurements by six thermocouples: three thermocouples were installed at each level in three different locations: near the lamp, in the middle of the cell, and close to plants. It is shown, the temperatures near the lamps are higher up to 2-3 degrees than the temperature inside the cell during the day time, indicating the significance of the lamp heating effect. Figure $3 \mathrm{~b}$ demonstrates the typical measurements of external and inside temperature during the third growth cycle (with natural external conditions). It is shown that the interior temperature is mostly uniform in both levels.

a)

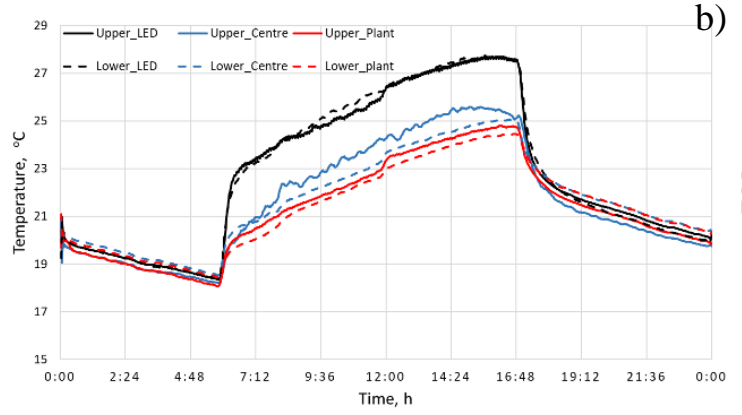

b)

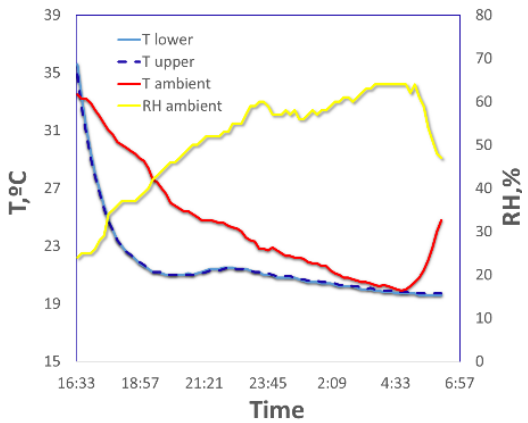

Fig. 3: Daily monitoring temperature by six thermocouples at different spatial locations of the growth cell (a); typical temperature and humidity measurements (b). 
Figure 4 represents the temperature distribution on leaves surfaces recorded by the thermal cameras for the third cycle (natural light at the upper level). It is shown that the outer leaves are 3 degrees colder than the inner young leaves. These observations indicate the importance of additional ventilation in the central zone of the plant; otherwise, such temperature difference may have a negative effect on plant development. There are no found a significant difference between leaf temperature at the upper and lower level; therefore, we can assume that the leaves temperature is defined mostly by inside microclimate conditions rather the light quality.

a)

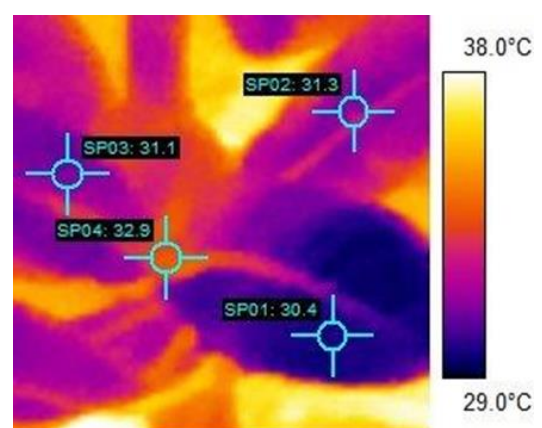

b)

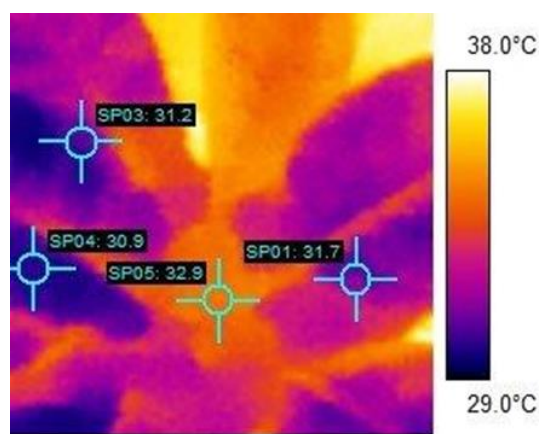

Fig. 4: Leaf thermal images of plant center in the lower level (a), and upper level (b);

\section{Conclusion}

The objectives of the paper are to perform thermal analysis for the characterization of microclimate inside the two-level growth cell. It is found that the plants under selective lighting (RB) are very sensitive to climate change. The best crop performance parameters were obtained for the plant growing under the natural sunlight, although the external climate conditions were rather warm. These results indicate the importance of optimal controlled conditions when artificial light is investigated. In addition, the thermal images of the plant leaf area indicate that the highest temperature is found to be in the center of plants where young leaves are developing. The large temperate difference between outside and inside leaves may provoke heat stress and, as a result, weak plant development. The additional ventilation in these regions of the plant should be considered in order to avoid the plant heat stress situation.

\section{References}

[1] M. Al-Chalabi, Vertical farming: Skyscraper sustainability?, Sustainable Cities and Society, vol. 18, 2015, pp. 74-77, ISSN 2210-6707, https://doi.org/10.1016/j.scs.2015.06.003.

[2] A. M. Beacham, L. H. Vickers, J. M. Monaghan. Vertical farming: a summary of approaches to growing skywards. The Journal of Horticultural Science and Biotechnology 94:3, pp. 277-283, 2019.

[3] D. Despommier, The Vertical Farm: Feeding the World in the 21st Century. New York: Picador, 2010.

[4] T. Kozai, G. Niu, M. Takagaki, Plant factory: an indoor vertical farming system for efficient quality food production. Academic Press, 2019.

[5] K Morgan, Feeding the City: The Challenge of Urban Food Planning. International Planning Studies 14: pp.341-348, 2009.

[6] A. M. Beacham, L. H. Vickers, J. M. Monaghan, Vertical farming: a summary of approaches to growing skywards. The Journal of Horticultural Science and Biotechnology, 94(3), 277-283, 2019. https://doi.org/10.1080/14620316.2019.1574214

[7] F. Kalantari, O. M. Tahir, A. M. Lahijani, S. Kalantari, A review of vertical farming technology: A guide for implementation of building-integrated agriculture in cities. In Advanced Engineering Forum, vol. 24, pp. 76-91, 2017 https://doi.org/10.4028/www.scientific.net/AEF.24.76

[8] Agrilyst. State of indoor farming 2017. whttps://doi.org/10.4028/www.scientific.net/AEF.24.76 
[9] A.M. Meacham, J.M. Monaghan, L.K.Aguiar, J. Eastham, Alternative production systems: Moving away from farming the land. Contemporary issues in food supply chain management, pp. 145-166. Oxford: Goodfellow, 2017

[10] P.J. Weathers, R.W. Zobel, Aeroponics for the culture of organisms, tissues, and cells. Biotechnology Advances, 10, 93-115, 1992 10.1016/0734-9750(92)91353-G

[11] J. E. Rakocy, M. P. Masser, T. M. Losordo, Recirculating aquaculture tank production systems: Aquaponics Integrating fish and plant culture (SRAC Publication No. 454). Stoneville: Southern Regional Aquaculture Centre, 2006

[12] G. Pennisi, S.Blasioli, A. Cellini, L. Maia, A. Crepaldi, I. Braschi, ... \& L. F. Marcelis Unravelling the role of red: blue LED lights on resource use efficiency and nutritional properties of indoor grown sweet basil. Frontiers in plant science, 10, 305, 2019.

[13] H. Spalholz, R. Hernández, Transplant lettuce response to different blue: red photon flux ratios in indoor LED solesource lighting production. In International Symposium on New Technologies for Environment Control, EnergySaving and Crop Production in Greenhouse and Plant 1227, pp. 555-562, 2017

[14] M. R. Sabzalian, P. Heydarizadeh, M. Zahedi, A. Boroomand, M. Agharokh, M. R. Sahba, B. Schoefs, High performance of vegetables, flowers, and medicinal plants in a red-blue LED incubator for indoor plant production. Agronomy for sustainable development, 34(4), pp. 879-886, 2014. 